Türk Coğrafya Dergisi
Turkish Geographical Review
Www.tcd.org.tr

\title{
Aşağı Meriç Nehri akımlarının mevsimsel ve yıllık değişiminin taşkınlar üzerine etkisi
}

\section{The effect of seasonal and annual variation of Lower Meriç River flows on floods}

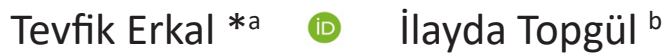 \\ ${ }^{a}$ Çankırı Karatekin Üniversitesi, Edebiyat Fakültesi, Coğrafya Bölümü, Çankırı. \\ ${ }^{b}$ Çankırı Karatekin Üniversitesi, Sosyal Bilimler Enstitüsü, Çankırı. \\ ORCID: T.E. 0000-0003-4435-7864; I.T. 0000-0002-2086-7598
}

\section{BILGI / INFO}

Geliş/Received: 12.11 .2019

Kabul/Accepted: 29.05 .2020

Anahtar Kelimeler:

Aşağı Meriç Nehri

Taşkınlar

Mann-Kendall trend analizi

Sen'in eğim testi

\section{Keywords:}

Lower Meriç River

floods

Mann-Kendall trend analysis

Sen's slope method

*Sorumlu yazar/Corresponding author:

(T.Erkal) erkaltevfik@gmail.com

\section{DOI: $10.17211 /$ tcd. 645865}

\section{Atif/Citation:}

Erkal, T. ve Topgül, ì. (2020). Aşağı Meriç Nehri akımlarının mevsimsel ve yıllık değişiminin taşkınlar üzerine etkisi. Türk Coğrafya Dergisi (74), 33-38.

DOI: $10.17211 /$ tcd.645865

\section{ÖZ / ABSTRACT}

Akarsu akım değişimlerinin taşkınlara neden olduğu ve çevresel sorunların ortaya çıktı̆ı havzalarda akım trendlerin bilinmesi önem taşımaktadır. Akarsu akımlarındaki değişimlerin bilinmesi su kaynaklarının kullanımı ve planlanması açııından gereklidir. Meriç Nehri'nin Türkiye sınırları içinde kalan bölümü yerleşim ve sanayi faaliyetleri açısından aktif bir bölgedir. Bu bağlamda Aşağı Meriç Nehri araştırma konusu açısından önemli bir örnek alan oluşturmaktadır. Bu çalışmada Aşağı Meriç Nehri akım değişimlerinin taşkınlar üzerindeki etkisinin incelenmesi amacıyla, 4 farklı akım gözlem istasyonu (AGi) verileri kullanılarak parametrik olmayan trend analizi yöntemleri uygulanmıştır. Akımların aylık, yıllık ve mevsimsel trendlerinin belirlenmesinde Mann-Kendall Trend Analizi yöntemi kullanılmıştr. Trendlerin lineer eğimleri Sen'in Trend Eğim Metodu kullanılarak hesaplanmıştır. Yapılan analizler sonucunda, incelenen 4 istasyonda yukarı yönlü trend eğilimleri tespit edilmiştir. En anlamlı sonuçlara taşkınların etkili olduğu Kirişhane AGI'nda rastlanmıştır. Kirişhane AGi tüm aylarda pozitif yönlü trendlerin varlığı görülmüştür. Yıllık olarak \%5'lik önem düzeyinde artan yönde istatistiksel olarak anlamlı bir trend belirlenmiştir. Her mevsimde artan yönde bir trend olduğu görülmüş, özellikle sonbahar mevsiminde \%1'lik güven aralığında pozitif yönlü istatiksel olarak anlamlı trend tespit edilmiştir. Sonuç olarak akım trendlerinin yıllık ve mevsimlik etkilerine bağlı olarak taşkınların formunun değiştiği ve taşkınlarda ciddi bir artş olduğu gözlenmiştir.

It is important to know the flow trends in the basins where river flow changes cause floods and environmental problems arise. Knowing the changes in stream flows is necessary for the use and planning of water resources. Meriç River is in active region in terms of the remaining part of the residential and industrial activities within Turkey's borders. In this context, the Lower Meriç River constitutes an important sample area for the research subject. In this study, the effects of current changes of the Lower Meriç River on floods were investigated. Non-parametric trend analysis methods were applied using 4 different stream gagging station (AGI) flow data. In order to determine monthly, annual and seasonal trends of the flows, Mann-Kendall Trend Analysis method was applied. Linear slopes of trends are calculated using Sen's Trend Slope Method. As a result of the analyses, upward trends were detected in the 4 stations examined. The most meaningful results were found in Kirişhane AGI where floods were effective. In Kirişhane AGI have been seen positive trends in all months. An increasingly statistically significant trend was determined at an annual level of $5 \%$. It has been observed that there is an increasing trend in every season. Especially in the fall season, a statistically significant trend with a positive direction was detected in the confidence interval of $1 \%$. As a result, it was observed that the form of floods changed and there was a significant increase in floods depending on the annual and seasonal effects of current trends.

\section{Giriş}

Son yıllardaki küresel iklim değişikliğine bağlı olarak meydana gelen şiddetli sağanaklar, akarsu havzalarındaki akımlarda belirgin değişimler yaratmakla birlikte akarsulardaki sel ve taşkın afetlerinin günümüzde daha sık ve şiddetli yaşanmasına neden olmaktadır. Akarsu taşkınları, etki alanlarının büyüklüğü ve zararları bakımından dünya genelinde en fazla etkiye sahip doğal afet türlerinden biridir. 20. yy'da Dünya genelinde meydana gelen doğal afetlerin \%43'ünü sel ve taşkınlar oluşturmaktadır. 
1995-2015 yılları arasında meteorolojik kökenli doğa olaylarının etkilediği insan sayısı bakımından \%56'lık bir oranla sel ve taşkın olayları ilk sırada yer almaktadır (MGM, 2018).

Türkiye'de taşkın tehlikesi ile karşı karşıya kalınan birçok akarsu havzası mevcuttur. Bu alanlardan biri de sınıraşan ve sınır oluşturan özelliğe sahip Meriç Nehri'dir. Meriç Nehri yağmur ve kar erimeleri ile beslenmektedir. Bu nedenle nehrin akım değerleri üzerinde, iklimsel özellikler ve iklimde meydana gelen değişimler doğrudan bir etkiye sahiptir (Turoğlu ve Uludağ, 2015). Meriç Nehri jeomorfolojik, klimatolojik ve hidrografik tabanlı birçok sebebe bağlı olup taşkın potansiyeli yüksek bir akarsudur. Buna bağlı olarak Meriç Nehri taşkınları üzerinde havzanın tüm fiziki ve beşeri özelliklerinin etkili olduğunu söylemek de mümkündür. Ayrıca akarsuyun kullanımından doğan ve akarsu yatak kapasitesinin zaman içinde dolması sonucunda ortaya çıkan sorunlar, akarsuyun akım özellikleri ve taşkınlar üzerinde beşeri etkiye sahip önemli faktörlerdendir.

Literatürde Meriç Nehri'nin bölgesel ve uluslararası düzeyde, özellikle taşkın sorununun tartışıldığı çok sayıda çalışma bulunmaktadır (Göçmen, 1976; Kurter, 1976; Cengiz, 1996; Zal, 2006; Artinyan vd., 2008; Batur, 2011; Türkmenoğlu, 2012; Turoğlu ve Uludağ, 2013; Topgül, 2019). Akarsu yağış ve akım trendlerinin değişimi yönündeki çalışmalar ise Türkiye'nin birçok havzası için yapılmakta ve araştırmalar devam etmektedir (Türkeş, 1996; Partal, 2002; Büyükyıldız ve Berktay, 2004; Gümüş, 2006; Özfidaner, 2007).

Meriç Nehri'nde olduğu gibi, akarsu akım değişimlerinin taşkınlara neden olduğu ve çevresel sorunların ortaya çıktığı havzalarda yağış, akım gibi zamana ve miktara bağlı trendlerin bilinmesi önem taşımaktadır. Özellikle akarsu akımlarındaki değişimlerin bilinmesi su kaynaklarının kullanımı ve planlanması açısından gereklidir. Bu bağlamda; bu çalışmada, Meriç Nehri'nin Türkiye sınırlarına giriş yaptığı Kapıkule'den, Enez'de denize döküldüğü yere kadar olan 187 km uzunluğundaki Aşağı Meriç Nehri olarak adlandırılan (Göçmen, 1976) yatağının yılık ve mevsimsel akımları trend analizi yöntemleri kullanılarak araştırılmış ve bu değişimin taşkınlar üzerindeki etkisi tartı̧ılmıştır.

\section{Araştırma Alanı}

\subsection{Meriç Nehri ve Havzası'nın Coğrafi Özellikleri}

Meriç Nehri kaynağını Bulgaristan'ın güneybatısında bulunan Rila Sıradağları'nın kuzey yamaçlarından almakta ve Meriç Havzası içerisinde akış göstermektedir. 2.925 m yükseklikten doğan (Artinyan vd., 2008) Meriç Nehri'nin aktğ̆ havza içindeki toplam uzunluğu 492 km'dir (Malkaralı vd., 2008).

Meriç Nehri'nin dört büyük yan kolu; Bulgaristan topraklarından doğan Arda ve Tunca, Türkiye topraklarından doğan Ergene Nehri ve Yunanistan topraklarından doğan Kızılçay'dır. Arda Nehri, Meriç Nehri'ne sağ kol olarak Türkiye sınırları içerisinde Edirne'nin batısında kathlır. Tunca Nehri ise, Arda Nehri'nden sonra Edirne'nin yakınında Meriç'in sol kolunu oluşturur. Meriç Nehri Dimetoka'nın güneyinde, batidan Kızılçay'ı, daha sonra İpsala'nın kuzeyinde, doğudan Ergene Nehri'ni alıp Saros Körfezi'nden Ege Denizi'ne dökülür (Erkal ve Topgül, 2015) (Şekil $1)$.

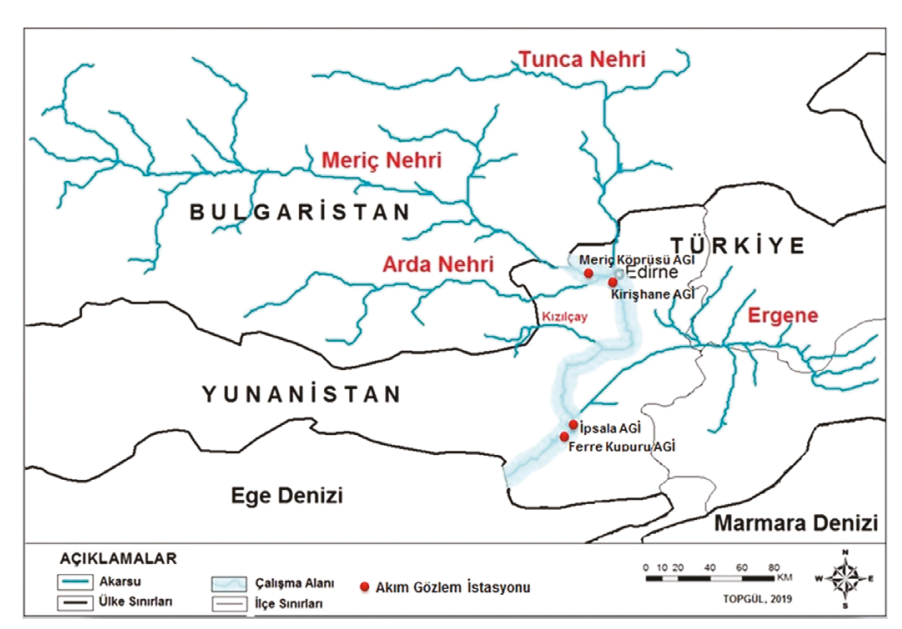

Şekil 1. Meriç Nehri'nin konumunu gösterir harita.

Figure 1. Location map of Meriç River.

Meriç Nehri Havzası'nın Bulgaristan içerisinde kalan yukarı kesimi yüksek dağlık bir alan özelliği gösterirken, Türkiye sınırları içerisinde kalan aşağı kesimi yukarı havzaya göre nispeten daha düz, alçak alanlardan oluşmuş bir taşkın ovası niteliğindedir (Şekil 2). Aşağı Meriç Nehri, içinde aktı̆̆ı taşkın ovasının özelliklerine uyum sağlamış, yatağı içinde taşkın suları ile taşınıp oluşturulan kum adalarının olduğu menderesli bir akarsu yatağına sahiptir. Meriç Nehri'nin Ege Denizi'ne döküldüğü yerde ise bir delta oluşumu mevcuttur.

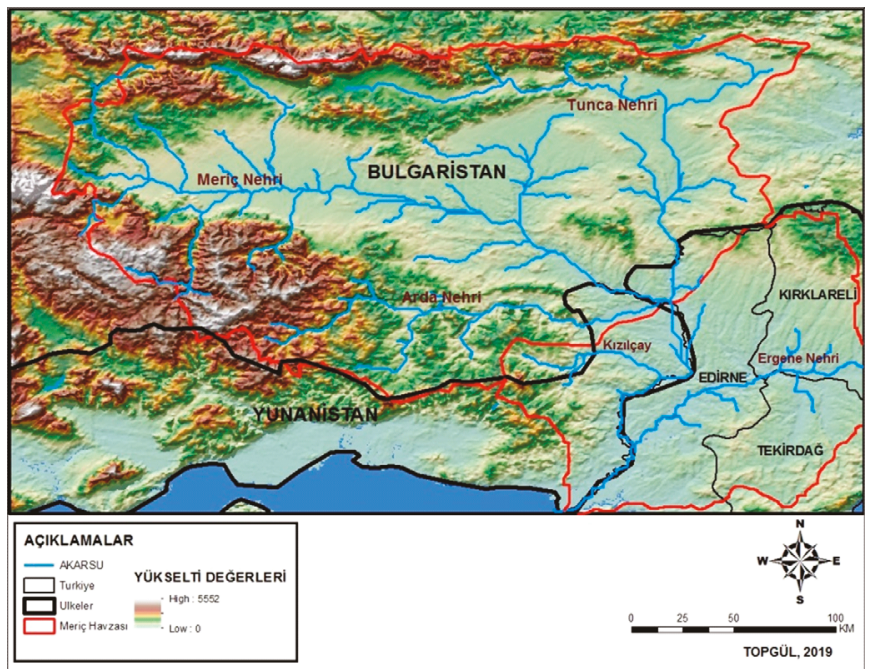

Şekil 2. Meriç Nehri Havzası ve yakın çevresinin fiziki haritası.

Figure 2. Physical map of the Meriç River Basin and its surroundings

Meriç Nehri Havzası içerisinde Bulgaristan, Yunanistan ve Türkiye toprakları bulunur. Havza toplam 52.600 km2'lik bir alan kaplamaktadır (Yıldız, 2011) (Tablo 1). Meriç Nehri Havzası'nın büyük bölümünün Bulgaristan sınırları içerisinde kalmasından dolayı, taşkınlara neden olan akımların büyük bir kısmı da Bulgaristan'dan kaynaklanmaktadır. Havzanın Bulgaristan içerisindeki yıllık yağışı 550-620 mm, dağlık bölgelerde 900-1000 mm arasındadır. En fazla yağış Mayıs ve Haziran aylarında, en az yağış ise Temmuz ve Ağustos aylarında, bazı yıllarda Şubat ayında görülmektedir (Erbay, 2010). Havzanın aşağı kesiminde Edirne sınırları içerisinde yıllık toplam yağış ortalaması 600,2 mm'dir. Aylık ortalama yağışın en fazla olduğu ay $70,3 \mathrm{~mm}$ ile Aralık ayıdır. Aylık ortalama yağışın en düşük olduğu ay 22,7 mm ile Ağustos ayıdır (MGM, 2019).mm ile Ağustos ayıdır (MGM, 2019). 
Tablo 1. Meriç Havzası'nın kıyıdaş ülkeler arasındaki dağılımı. Table 1. Areal distribution of the Meriç basin by country.

\begin{tabular}{|l|c|c|}
\hline \multicolumn{1}{|c|}{ Ülke } & Havza Alamı (km²) & Yüzde (\%) \\
\hline Bulgaristan & 34.067 & 65 \\
\hline Tưrkiye & 14.850 & 28 \\
\hline Yunanistan & 3.685 & 7 \\
\hline Toplam & 52.600 & 100 \\
\hline
\end{tabular}

Havzanın Bulgaristan sınırları içerisinde kalan kesiminde yağışlar Meriç Nehri yatağı boyunca yoğunlaşmaktadır. Bu durum Bulgaristan'a düşen yağışların Meriç Nehri akımlarını doğrudan etkilemesine ve aşağı kesimlerde vuku bulan taşkınlarının büyüklüğü ile şiddeti üzerindeki etkisine neden olmaktadır. Havzanın aşağı kesiminde de benzer bir durum söz konusudur. Yağışlar Aşağı Meriç Nehri yatağı boyunca ve Edirne Merkez ilçesinin kuzey kesimlerinde, yani Meriç, Arda ve Tunca nehirlerinin birleşim noktasında yoğunlaşmıştı (Türkmenoğlu, 2012). Bu durum taşkın dönemlerinde bölgeye düşen yağışın doğrudan Aşağı Meriç Nehri'ne katılmasına ve taşkın büyüklüğünün artmasına neden olmaktadır.

Havzada genel olarak yazları sıcak ve kurak, kış ve bahar dönemlerinde ılık ve yağışlı geçen bir iklim hâkimdir. Havzada görülen iklim özelliği ile uyumlu olarak kış ve bahar aylarında Meriç Nehri akımlarda bir artı̧̧, yaz aylarında ise akımlarda bir düşüş görülmektedir.

\subsection{Aşağı Meriç Nehri'nin Akım Özellikleri}

Meriç Nehri bulunduğu havza farklı coğrafi ve iklimsel koşullara sahip bir alana yayılmıştır. Bulunduğu havzanın genişliğinden dolayı Aşağı Meriç Nehri'nin akım özellikleri, su toplama havzasının birçok özelliğinden etkilenmektedir. Havzadaki diğer akarsuların su potansiyelleri ve havzanın birçok yerindeki iklimsel farklılıklar Aşağı Meriç Nehri'ni hidrografik açıdan şekillendirmektedir (Topgül, 2019).

Meriç Nehri'nin Türkiye topraklarına giriş yaptığı yerdeki su potansiyeli ve Saros Körfezi'nden Ege Denizi'ne döküldüğü noktadaki su potansiyeli neredeyse birbirinin iki katıdır (Tablo 2). İki nokta arasındaki su potansiyeli farkının nedeni, Meriç Nehri'nin dört büyük yan kolu olan Tunca, Arda, Ergene ve Kızılçay'ın Meriç Nehri'ne Türkiye sınırları içerisinde, Aşağı Meriç Nehri yatağı boyunca katılıyor olmasından kaynaklanmaktadır. Yan kolların getirdiği su potansiyeli, akarsuyun aşağı çığırındaki akımlarda değişimlere neden olmakla birlikte akarsuyun denize döküldüğü noktadaki su miktarında da belirgin bir artışın nedenidir.

Tablo 2. Meriç Nehri'nin su potansiyeli (Malkaralı vd., 2008).

Table 2. Water potential of Meriç River (Malkaralı vd., 2008).

\begin{tabular}{|l|c|}
\hline Meriç Nehri Su Potansiyelleri (hm $\mathbf{3} /$ yll) \\
\hline Meriç Nehri Türkiye'ye Giriş & 4.084 \\
\hline Tunca Nehri Türkiye'ye Giriş & 673 \\
\hline Arda Nehri Türkiye'ye Giriş & 1.085 \\
\hline Meriç-Tunca-Arda Toplamı & 5.842 \\
\hline Ergene Nehri Türkiye'ye Giriş & 1.330 \\
\hline Kızılçay Türkiye'ye Giriş & 1.158 \\
\hline Saros Körfezi’ne Dökülen Toplam Su & 8.330 \\
\hline
\end{tabular}

\section{Veri ve Yöntem}

Bu çalışmada Meriç Nehri'nin Türkiye sınırlarına giriş yaptı̆̆ı Kapıkule'den, Enez'de denize döküldüğü yere kadar olan 187 km uzunluğundaki Aşağı Meriç Nehri olarak adlandırılan yatağının akım değerlerindeki mevsimsel ve yıllık değişimi ile bu değişimin taşkınlar üzerindeki etkisi araştırılmıştır.

Aşağı Meriç Nehri yatağı ve yan kolları boyunca birçok akım gözlem istasyonu bulunmaktadır. Fakat bunlardan bir kısmı veri yetersizliği nedeniyle inceleme yapmak için uygun değildir. Bu nedenle, araştırma konusunu ve sahasını en iyi karakterize eden 4 akım gözlem istasyonu (AGi) seçilmiştir. Çalışma kapsamında kullanılan istasyonlar Tablo 3'te gösterilmiştir. Bu araştrrmada, Edirne'deki DSi 11. Bölge Müdürlüğü'nden alınan 1986-2016 yılları arası Kirişhane AGi, 1986-2016 yılları arası Edirne Merkez'de bulunan Meriç Köprüsü AGI, 2002-2016 yılları arası İpsala Gümrük Köprüsü AGi ve 1986-2016 yılları arası İpsala Ferre Kupuru AGI'na ait aylık ve yılık ortalama değerler ile maksimum akımlardan yararlanılmıştır. Bu veri setleri üzerinde akımların uzun süreli yıllık ve mevsimlik değişim ve eğilimlerinin bilinmesi amacıyla parametrik olmayan testlerden Mann-Kendall Trend Testi ve Sen'in Trend Eğimi Yöntemi uygulanmıştır.

Tablo 3. Araştırmada kullanılan AGi bilgileri. Table 3. AGI information used in this research.

\begin{tabular}{|c|c|c|c|c|}
\hline $\begin{array}{c}\text { İstasyon } \\
\text { No }\end{array}$ & İstasyon Adı & Koordinat & $\begin{array}{c}\text { Veri } \\
\text { Aralığı }\end{array}$ & $\begin{array}{c}\text { Veri } \\
\text { Sayısı }\end{array}$ \\
\hline D01A003 & Kirişhane & $\begin{array}{c}26^{\circ} 33^{\prime} \text { D-41038' } \\
\mathrm{K}\end{array}$ & $1986-2016$ & 31 \\
\hline E01A003 & Merị̧ Köprüsü & $\begin{array}{c}26^{\circ} 33^{\prime} \mathrm{D}-41^{\circ} 39^{\prime} \\
\mathrm{K}\end{array}$ & $1986-2011$ & 26 \\
\hline D01A026 & İpsala Gümrük Köprüsü & $\begin{array}{c}26^{\circ} 19^{\prime} \mathrm{D}-40^{\circ} 56^{\prime} \\
\mathrm{K}\end{array}$ & $2002-2016$ & 15 \\
\hline D01A057 & Ferre Kupuru & $\begin{array}{c}26^{\circ} 14^{\prime} \mathrm{D}-40^{\circ} 51^{\prime} \\
\mathrm{K}\end{array}$ & $1986-2016$ & 31 \\
\hline
\end{tabular}

Mann-Kendall Trend Testi: İlim ve hidroloji çalışmalarında özellikle zaman serilerinde meydana gelebilecek artma veya azalma yönündeki değişimlerin istatistiksel olarak test edilmesinde yaygın olarak kullanı-lan bir yöntemdir (Yue vd., 1993; Büyükyıldız ve Berktay, 2004; Gümüş, 2006; Özfidaner, 2007; Tağıl ve Alevkayalı, 2014; Ay ve Kişi, 2016; Karakuş, 2017).

Testin anlamlılık düzeyleri hesaplanan Z değerinin standart dağılım tablosundaki $\alpha=0.05$ (\%5) veya $\alpha=0.10$ (\%10) düzeylerine karşılık gelen kritik z değerleriyle kıyaslanması sonucunda belirlenir. Buna göre $\alpha=0.05$ anlamlılık düzeyine karşılık gelen değer 1.96 iken $\alpha=0.10$ anlamlılık düzeyine karşılık gelen değer 1.64'tür (Ay ve Kişi, 2016; Karakuş, 2017). Z değeri, a anlamlılık seviyesine karşılık gelen kritik değerden küçük olduğu zaman HO hipotezi "trend yok" kabul edilir. Bu durumda zaman serileri arasında bir trend olmadığı sonucuna varılır. Hesaplanan Z değeri $\alpha$ anlamlılık seviyesine karşılık gelen kritik değerden büyükse HO hipotezi "trend yok" reddedilir ve zaman serileri arasında bir trend olduğu sonucuna varılır. (Yue vd., 1993; Karakuş, 2017) Mann-Kendall testinde çıkan değerlerin pozitif olması durumunda artan yönde; ne-gatif olması durumunda azalan yönde bir trend olduğu sonucuna varılmaktadır. 
Sen'in Trend Eğimi Yöntemi: Hidro-meteorolojik zaman serilerindeki trendlerin lineer eğimlerinin (birim zamandaki değişim) belirlenmesi amacıyla uygulanan analiz yöntemidir (Partal, 2002). Sen tarafindan geliştirilmiş ve zaman serileri arasındaki veri eksikliklerinden ve hatalarından etkilenmeyen parametrik olmayan bir yöntemdir (Yue vd., 1993; Gümüş, 2006). Yönteme bağlı olarak hesaplanan $Q$ değerlerinin medyanı alınır ve ilgili gözlemin zaman serileri arasındaki değişimi belirlenir. Sonuçlara göre oluşturulan grafik üzerinde veri noktaları eğilim çizgisine denk geliyorsa veri setleri arasında eğilim olmadığı sonucu çıkarılır. Veri noktaları eğilim çizgisinin üstünde kalıyorsa artan bir eğilim, altında kalıyorsa azalan bir eğilim olduğu sonucuna varılır (Ay ve Kişi, 2016).

Aşağı Meriç Nehri'nde seçilen 4 ayrı AGi akım verileri üzerinden Maan-Kendall ve Sen'in Trend Eğimi Yöntemi uygulanmıştır. Test sonuçları aylık, yıllık ve mevsimlik olarak oluşturulan tablo ve grafikler üzerinden trendin varlığı yönünde yorumlanmıştır. Son olarak artan akımların taşkınlara olan etkisi tartışılmıştır.

\section{Bulgular ve Tartışma}

4.1. Aşağı Meriç Nehri Akımlarında Yaşanan Mevsimsel ve Yıllık Değişim

Meriç Nehri'nin Türkiye sınırları içerisinde kalan kesiminde akarsu yatağının su taşıma kapasitesi 1000 m3/sn olmakla birlikte bunun üzerindeki akımlar taşkınlara neden olmaktadır (Yıldız, 2011). Meriç Nehri'nde son dönemde ölçülen maksimum akım değerlerine bakıldığında akımlarda ve buna bağlı olarak taşkınlarda ciddi bir artışın olduğu göze çarpmaktadır. Edirne merkezde bulunan Kirişhane Ölçüm İstasyonu'ndan alınan 1982-2016 yılları arası, 35 yıllık periyotta akım değerleri incelendiğinde, 1982-2000 yılları arasındaki dönemde akım değerlerinin yatak taşıma kapasitesini aşmadığı sadece birkaç kez bu değere yaklaştğ̆ görülmektedir. Ancak özellikle 2000'li yıllardan sonraki dönemde yatak taşıma kapasitesinin sık sık aşılması ile birlikte maksimum akım değerlerinde ve taşkınlarda bir artı̧̧ olduğu dikkat çekicidir (Topgül, 2019) (Şekil 3).

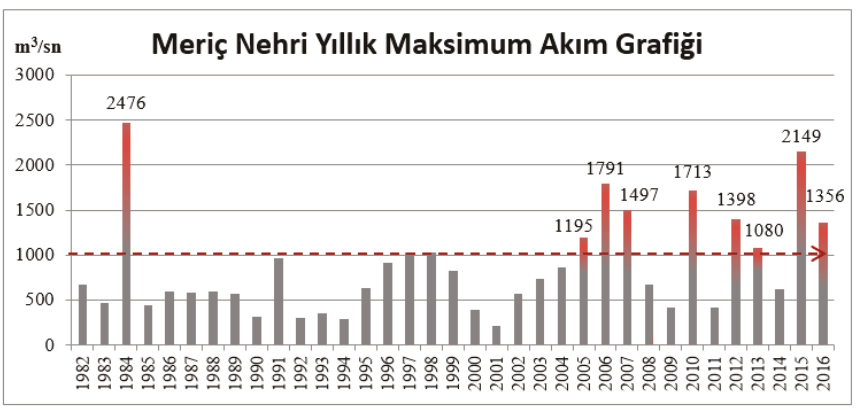

Şekil 3. Meriç Nehri Kirişhane AGi yıllık maksimum akım değişimleri. Figure 3. Meriç River Kirişhane AGI annual maximum flow values.

Şekil 3'te gösterilen maksimum akım değerlerindeki artışın anlamlı olup olmadığını tartş̧mak için Edirne merkezde bulunan Kirişhane AGi 1986-2016 yılları arası akım verilerine Mann-Kendall trend analizi yöntemi uygulanmıştır. Testin sonuçları Tablo 4'te gösterilmiştir. Mann-Kendall yöntemi kullanılarak yapılan trend analizi sonuçlarına göre " $z$ " değerinin tamamının pozitif olmasına bağlı olarak aylık ve yıllık akımlarda artan yönde bir trend olduğu görülmüştür. Ancak bu artan trend eğilimi bazı aylarda istatistiki ola־rak anlamlı, bazı aylarda ise anlamlı bulunmamıştır. Ocak ayında pozitif yönlü \%1'lik önem düzeyinde istatistiksel olarak anlamlı bir trend, Eylül ayında \%5'lik önem düzeyinde istatistiksel olarak anlamlı, pozitif yönlü trend belirlenmiştir. Mart, Nisan, Ekim, Kasım ve Aralık aylarında \%10 önem düzeyinde istatistiksel olarak anlamlı pozitif yönlü trend görülmektedir. Şubat, Mayıs, Haziran ve Temmuz aylarında yukarı yönlü trend görülse de bu trendler istatistiksel olarak anlamlı bulunmamıştır. Mann-Kendall trend analizinin yıllık sonucuna bakıldığında \%5'lik önem düzeyinde yukarı yönlü, istatistiksel olarak anlamlı bir trend eğilimi tespit edilmiştir.

Tablo 4. Kirişhane AGI akım verilerinin Mann-Kendall trend analizi sonuçları. Table 4. Mann-Kendall trend analysis results of Kirişhane AGI flow data.

\begin{tabular}{|l|c|c|c|c|c|}
\hline $\begin{array}{l}\text { Zaman } \\
\text { Serileri }\end{array}$ & $\begin{array}{c}\text { Başlangıç } \\
\text { Yılı }\end{array}$ & Bitiş Yılı & $\begin{array}{l}\text { Veri } \\
\text { Sayısı }\end{array}$ & $\begin{array}{c}\text { Mann-Kendall } \\
\text { Trend Testi } \\
(\mathbf{Z})\end{array}$ & Anlamlılık \\
\hline Ocak & 1986 & 2016 & 31 & 3,32 & $* * *$ \\
\hline Şubat & 1986 & 2016 & 31 & 1,60 & \\
\hline Mart & 1986 & 2016 & 31 & 2,29 & $*$ \\
\hline Nisan & 1986 & 2016 & 31 & 2,36 & $*$ \\
\hline Mayıs & 1986 & 2016 & 31 & 1,36 & \\
\hline Haziran & 1986 & 2016 & 31 & 1,55 & \\
\hline Temmuz & 1986 & 2016 & 31 & 1,38 & \\
\hline Ağustos & 1986 & 2016 & 31 & 1,78 & $*$ \\
\hline Eylül & 1986 & 2016 & 31 & 2,89 & $* *$ \\
\hline Ekim & 1986 & 2016 & 31 & 2,47 & $*$ \\
\hline Kasım & 1986 & 2016 & 31 & 2,19 & $*$ \\
\hline Aralık & 1986 & 2016 & 31 & 2,11 & $*$ \\
\hline YILLIK & 1986 & 2016 & 31 & 3,23 & $* *$ \\
\hline
\end{tabular}

Aşağı Meriç Nehri boyunca 4 farklı AGi'na ait akım verilerinin zaman içerindeki lineer yönünü belirlemek amacıyla Sen'in trend eğim yöntemi uygulanmıştr. Elde edilen sonuçlara göre hazırlanmış olan grafikler Şekil 4'te gösterilmiştir. 1986-2016 yılları arasında Kirişhane AGI'nda artan yönde bir eğilim olduğunu görülmüştür. İpsala Gümrük Köprüsü AGi 2002-2016 yılları arasında artan yönde, İpsala Ferre Kupuru AGi 1986-2016 yılları arasında artan yönde ve Meriç Köprüsü AGi 1986-2011 yılları arasında yine yukarı yönlü bir eğilim olduğu görülmüştür.
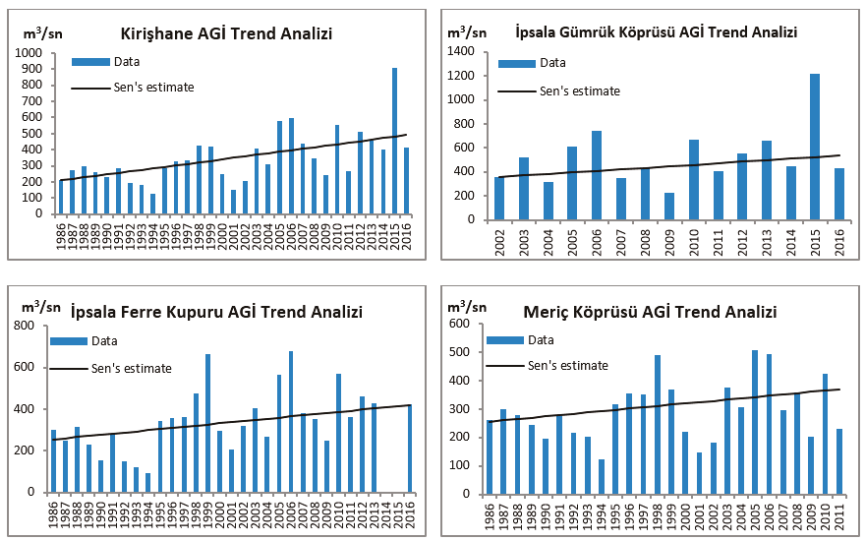

Şekil 4. Meriç Nehri AGi akım verilerinin Sen'in trend eğilim yöntemi sonuçları.

Figure 4. Sen's trend analysis results of Meriç River AGI flow data.

Yapılan analiz sonuçlarına göre istatistiksel olarak en anlamlı sonuçlara Kirişhane AGI'nda rastlanmıştır. Kirişhane istasyonunun bulunduğu nokta, Aşağı Meriç Nehri boyunca taşkınların en fazla etkili olduğu yer olması bakımından bu istasyondaki 
trendlerin varlığı oldukça önemlidir. Bu nedenle akımların taşkınlar üzerindeki mevsimsel etkilerini belirlemek amacıyla Kirişhane istasyonu akım verileri Mann-Kendall yöntemi ile mevsimsel olarak analiz edilmiştir. Testin sonuçları Tablo 5'te verilmekte olup Mann-Kendall yöntemi kullanılarak yapılan trend analizi sonuçlarına göre Kirişhane AGI'nda " $z$ " değerinin tamamının pozitif olmasına bağlı olarak akımlarda her mevsim artan yönde istatistiksel olarak anlamı trendlerin varlığı görülmüştür. Özellikle Eylül, Ekim ve Kasım aylarına denk gelen sonbahar mevsiminde \%1'lik güven aralığında pozitif yönlü, istatistiksel olarak anlamlı bir trend saptanmıştır. Bu durumun mevsimsel olarak sonbahar taşkınlarının artması yönünde etkili olacağı düşünülmektedir. Ayrıca kış mevsiminde \%5 önem düzeyinde, yaz ve ilkbahar mevsiminde \%10 önem düzeyinde istatistiksel olarak anlamlı, artan yönlü trendlerin varlığı görülmüştür. Mevsimsel trendlerin yaz aylarında artı̧̧ göstermiş olması ayrıca dikkat çekicidir. Havzada görülen iklim özelliği ile uyumlu olarak yaz aylarında yağış ve akımlarda bir düşüş olması beklenirken, akımların yaz mevsiminde artı̧ göstermeye başlaması ile birlikte taşkın dönemlerinde mevsimsel bir değişim ortaya çıkmaktadır.

Tablo 5. Kirişhane AGi akım verilerinin Mann-Kendall trend analizi sonuçları. Table 5. Mann-Kendall trend analysis results of Kirişhane AGI flow data.

\begin{tabular}{|c|c|c|c|c|c|}
\hline Zaman Serileri & $\begin{array}{c}\text { Başlangıç } \\
\text { Yllı }\end{array}$ & $\begin{array}{c}\text { Bitiş } \\
\text { Yllı }\end{array}$ & $\begin{array}{c}\text { Veri } \\
\text { Sayısı }\end{array}$ & $\begin{array}{c}\text { Mann-Kendall } \\
\text { Trend Testi } \\
(\mathbf{Z})\end{array}$ & Anlamlılık \\
\hline Mart-Nisan-Mayıs & 1986 & 2016 & 31 & 2,41 & $*$ \\
\hline $\begin{array}{c}\text { Haziran-Temmuz- } \\
\text { Ağustos }\end{array}$ & 1986 & 2016 & 31 & 2,18 & $*$ \\
\hline Eylül-Ekim-Kasım & 1986 & 2016 & 31 & 3,33 & $* * *$ \\
\hline Aralık-Ocak-Şubat & 1986 & 2016 & 31 & 2,99 & $* *$ \\
\hline
\end{tabular}

Nitekim Meriç Nehri akım ve taşkınlarında son yıllarda görülen artş̧, akımlarda yaşanan mevsimsel değişimlerin bir sonucudur. 1982-2016 yılları arası Meriç Nehri akımları 10 yıllık periyotlar halinde incelendiğinde; 1982-1999 yılları arası aylık maksimum akımların, genel olarak sonbahar ortasından ilkbahar sonuna kadar nispeten yüksek olduğu görülmektedir. Yıllar içerisinde, özellikle 2000-2016 yılları arasında hem akım miktarlarında bir artş, hem de en çok akımlarım yaşandığı aylarda değişimler olduğu göze çarpmaktadır (Şekil 5).

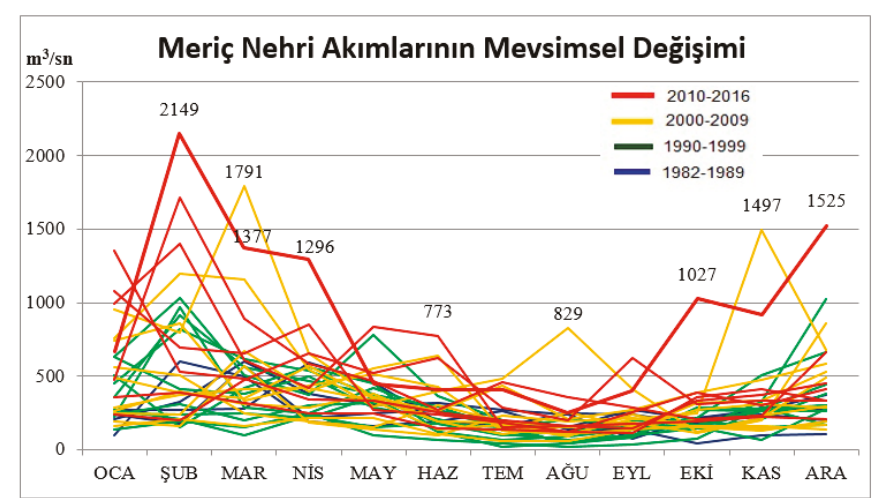

Şekil 5. Meriç Nehri maksimum akımlarının mevsimsel değişimi.

Figure 5. Seasonal variation of the maximum flow values of Meriç River.

Meriç Nehri taşkınları genel olarak sonbahar, kış ve ilkbahar taşkınları olarak bilinir. Yaz aylarında taşkın oluşumundan çok, yüksek sıcaklıklara bağı olarak akarsu yatağında kurumalar görülmektedir. Ancak 2005 yılında yaşanan Şubat ve Mart ayı taşkınların yanı sıra, Ağustos ayında 829 m3/sn'lik anormal bir akım değeri ölçülmüştür. 2006 yılı içerisinde Mart ayında 1.791 m3/sn'lik bir taşkın akım değeri kaydedilmiştir. Bu akım, ölçüm periyodu içerisindeki en büyük Mart ayı akım değeridir. 2007 yılı içerisinde aylık ortalama akımlar oldukça düşük bir seyir izlerken, Kasım ayı içerisinde 1.497 m3/sn'lik o zamana kadarki en büyük Kasım ayı taşkın akım değeri kaydedilmiştir. Akımların genel itibari ile düşük olduğu 2012 yılı içerisinde Haziran ayında 773 m3/sn'lik beklenmedik bir akım gerçekleşmiştir. 2015 yılı akım değerleri incelendiğinde, genel olarak yıl içerisinde aylık akım değerlerinin yüksek olduğu görülmekle birlikte, Şubat ayında son zamanların en büyük taşkını sayılan 2.149 m3/sn'lik bir taşkın akım değeri kayıtlara geçmiştir. Ayrıca 2015 yılı ölçüm dönemi boyunca yıl içinde en fazla taşkın yaşanan yıldır (Şekil 6). Bu gibi örnekleri çoğaltmak mümkün olmakla birlikte Aşağı Meriç Nehri akımlarının aylık, yıllık değişimini ve bu değişimin taşkınlar üzerindeki etkisini gözlemlemek mümkündür.

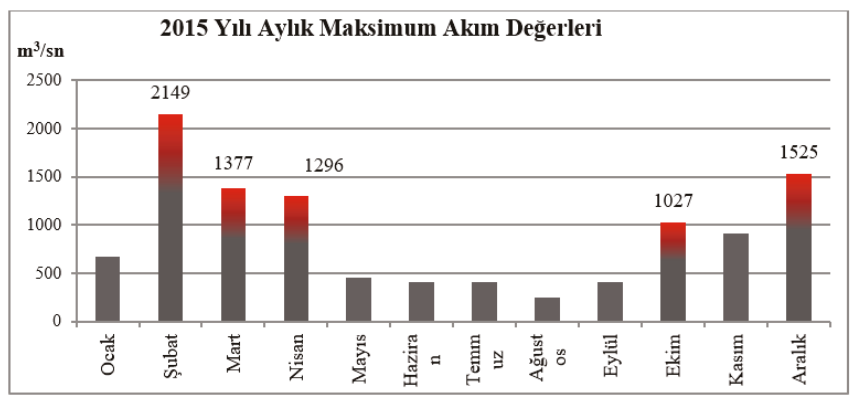

Şekil 6. 2015 yılı Kirişhane AGI aylık maksimum akım değerleri. Figure 6. Kirişhane AGI monthly maximum current values in 2015.

\section{Sonuç}

Bu çalışmada, Aşağı Meriç Nehri akımlarının artan taşkınlar üzerindeki aylık, yıllık ve mevsimsel etkisinin belirlenmesi amacıyla parametrik olmayan trend analizi yöntemlerinden MannKendall ve Sen'in Trend Eğimi yöntemi uygulanmıştır. Seçilen 4 ayrı AGi verileri kullanılarak yapılan uygulamalar sonucunda akım trendleri ve trendlerin lineer eğilimleri belirlenmiştir. İnceleme yapılan tüm istasyonlarda artan yönde pozitif trendler ve yıllar içerisinde yukarı yönlü eğilim olduğu tespit edilmiştir. İstatistiksel olarak en anlamlı sonuçlara Kirişhane AGi'nda rastlanmıştır. Kirişhane AGi, Aşağı Meriç Nehri taşkınlarının en fazla etkili olduğu yerde bulunması bakımından bu istasyondaki trendlerin varlığı oldukça önemlidir.

Yapılan Mann-Kendall trend analizi sonuçlarına göre Kirişhane AGI'nda ölçüm yapılan tüm aylarda pozitif ve artan yönde trendler saptanmıştır. Akım trendlerinde istatistiksel olarak en anlamlı artışın \%1'lik önem düzeyi ile Ocak ayında olduğu görülmüştür. Eylül ayında \%5 önem düzeyinde Mart, Nisan, Ekim, Kasım ve Aralık aylarında ise \%10 önem düzeyinde pozitif ve artan yönde istatistiksel olarak anlamlı trendler belirlenmiştir. Diğer aylarda yukarı yönlü pozitif trendler görülse de bu trendler istatistiksel olarak anlamlı bulunmamıştır. Yıllık olarak \%5 önem düzeyinde trend tespit edilmiştir.

Meriç Nehri akımlarının aylık ve yıllık artışının yanısıra akım- 
larda yaşanan mevsimsel değişimler de dikkat çekmektedir. Nitekim yapılan analizler sonucunda her mevsimde pozitif ve artan yönde, istatistiksel olarak anlamlı trendler görülmüş olmakla birlikte, özellikle sonbahar mevsiminde \%1'lik önem düzeyinde artan yönde bir trendin varlığı saptanmıştir. Bu durum mevsimsel olarak sonbahar taşkınlarının artması yönünde etkili olmuştur. Ayrıca mevsimsel trendlerin yaz aylarındaki \%10 önem düzeyindeki anlamlıı̆̆ına bağlı olarak akımların yaz mevsiminde artı̧ göstermeye başladığı belirlenmiştir. Bu durum zaman içinde yaşanan taşkınların formunun değişmesinde ve taşkın dönemlerinde mevsimsel bir kayma yaşanması yönünde etkili olmuştur.

Elde edilen sonuçlara göre özellikle 2000'li yıllardan sonra Aşağı Meriç Nehri'nde aylık, yıllık ve mevsimlik akımların taşkın oluşturacak düzeyde artş gösterdiği saptanmıştır. Bu sonuçlar, artan akım değerlerine bağlı olarak gelecekte taşkın sorununun etki boyutunun daha da artacağını göstermektedir. Artan taşkınlar üzerinde son yıllardaki iklimsel değişimler, havzanın fiziki özellikleri ve su kullanımından doğan sorunlardan biri olan barajlardan kontrolsüz su bırakılması ile birlikte yatak kesitinin zaman içinde dolması da etkili olmaktadır. Meriç Nehri, içinde bulunduğu havzanın coğrafi özellikleri ve yer aldığı bölgenin politik özelliklerinden dolayı hidro-politik açıdan önemli bir akarsudur. Bu nedenle havzada karşılaşılan herhangi bir sorunun çözümünün hem bölgesel hem de ulusal nitelikte ele alınması gerekmektedir. Artan taşkın sorununun kalıcı çözümü için gerekli önlemlerin kıyıdaş ülkelerce kısa vadede alınması zorunluluk olarak görülmektedir. Aksi takdirde taşkınların önüne geçilmesi mümkün olmayacak ve taşkın zararları artarak devam edecektir.

\section{Kaynakça}

Artinyan, E., Habets, F., Noilhan, J., Ledoux, E., Dimitrov, D., Martin, E. and Mogine, P. (2008). Modelling the water budget and the riverflows of the Maritsa Basin in Bulgaria. Hydrology and Earth System Sciences 12, 21-37.

Ay, M. ve Kişi, Ö. (2016). Debi ve sediment değişkenlerinin trend analizi. Dicle Üniversitesi Mühendislik Fakültesi Dergisi (7)2, 169180.

Batur, E. (2011). Uzaktan Algılama ve CBS entegrasyonu ile taşkın alanlarının belirlenmesi: Meriç Nehri örneği. Hava Harp Okulu Komutanlığı Havacılık ve Uzay Teknolojileri Enstitüsü, Yüksek Lisans Tezi, İstanbul.

Büyükyıldız, M. ve Berktay, A. (2004). Parametrik olmayan testler kullanılarak Sakarya Havzası yağışlarının trend analizi. Sakarya Üniversitesi Mühendislik-Mimarlık Fakültesi Dergisi 19(2), 23-37.

Cengiz, T.M. (1996). Meriç Havzası'nın Hidrolojik Yönden incelenmesi. Yıldız Teknik Üniversitesi Fen Bilimleri Enstitüsü, Yüksek Lisans Tezi, İstanbul.

Erbay, Y. (2010). Meriç Nehri ile Saros Körfezi'ne Taşınan Sediment, Tatısu ve Ağır Metaller. İstanbul Üniversitesi Deniz Bilimleri ve İşletmeciliği Enstitüsü, Deniz Jeolojisi ve Jeofiziği Anabilim Dalı, Yüksek Lisans Tezi, Ankara.

Erkal, T. ve Topgül, i. (2015). Meriç Nehri'nin son 15 yıllık taşkınları ve korunma projeleri. TÜCAUM VIII. Coğrafya Sempozyumu Bildiriler Kitabı (23-24 Ekim 2014), Ankara Dil ve Tarih-Coğrafya Fakültesi, Ankara, 165-174.

Göçmen, K. (1976). Aşağı Meriç Taşkın Ovası ve Deltası'nın Alüvya Jeomorfolojisi. İstanbul Üniversitesi Coğrafya Enstitüsü Yayın No.80, istanbul.

Gümüş, V. (2006). Fırat Havzası Akımlarının Trend Analizi ile Değerlendirilmesi, Harran Üniversitesi, Fen Bilimleri Enstitüsü, Yüksek
Lisans Tezi, Şanlıurfa.

Karakuş, C.B. (2017). Trend analysis methods for hydro-meteorological parameters. International Journal of Scientific and Technological Research 3(2), 22-32.

Kurter, A. (1976). Meriç Nehri'nin akım özellikleri. Güney-Doğu Avrupa Araşttrmaları Dergisi, 4(5), 285-294.

Malkaralı, S., Korkmaz, M. ve Sezen, N. (2008). Meriç Nehri taşkınları ve taşkınlar için geliştirilen uluslararası projeler. 5. Dünya Su Forumu Türkiye Bölgesel Su Toplantıları Taşkın Konferansı, Edirne.

MGM (Meteoroloji Genel Müdürlüğü) (2018). Meteorolojik Karakterli Doğal Afetler 2017 Yılı Değerlendirmesi. Orman ve Su İşleri Bakanlığı, Meteoroloji Genel Müdürlüğü Araşttrma Dairesi Başkanlığı, Ankara.

MGM (Meteoroloji Genel Müdürlüğü) (2019). Uzun Yıllar Tüm Parametreler Bülteni (Yayımlanmamıştı).

Özfidaner, M. (2007). Türkiye Yağış Verilerinin Trend Analizi ve Nehir Akımları Üzerine Etkisi. Çukurova Üniversitesi, Fen Bilimleri Enstitüsü, Tarımsal Yapılar ve Sulama Anabilim Dalı, Yüksek Lisans Tezi, Adana.

Partal, T. (2002). Türkiye'de Yağış Verilerinin Trend Analizi. İstanbul Teknik Üniversitesi, Fen Bilimleri Enstitüsü, Yüksek Lisans Tezi, İstanbul.

Tağıl, Ş. ve Alevkayalı, Ç. (2014). Eğirdir Gölü'ne kuzeyden dökülen akarsularda akım trendi ve yağış ilişkisi. Balıkesir Üniversitesi Sosyal Bilimler Enstitüsü Dergisi (17)32, 211-229.

Topgül, i. (2019). Hidrografik Açıdan Aşağı Meriç Nehri ve Taşkınlar. Çankırı Karatekin Üniversitesi Sosyal Bilimler Enstitüsü, Yüksek Lisans Tezi, Çankırı.

Turoğlu, H. ve Uludağ, M. (2013). Possible hydrographic effects of climate change on lower part of transboundary Meriç River Basin (Turkey). Trakya University Journal of Natural Sciences 14(2), 77 85.

Türkeş, M. (1996). Spatial and temporal analysis of annual rainfall variations in Turkey. International Journal of Climatology 16, 10571076.

Türkmenoğlu, Y. (2012). Meriç Nehri'nin Kapıkule-Enez Arasındaki Yatak Değişimlerinin Taşkınlar ille iliş̧kisi. İstanbul Üniversitesi Sosyal Bilimler Ensitüsü, Coğrafya Anabilim Dalı, Yüksek Lisans Tezi, İstanbul.

Yıldız, D. (2011). Meriç Nehri Havzası Su Yönetiminde Uluslararası Işbirliği Zorunluluğu. ORSAM (Ortadoğu Stratejik Araştrmalar Merkezi) Raporu, Rapor No:4.

Yue, Y.S., Zou, S. and Whittemore, D. (1993). Non-parametric trend analysis of water quality data of rivers in Kansas. Journal of Hydrology 150, 61-80.

Zal, N. (2006). Aşağı Meriç Vadisi Taşkın Ovası́nın Biyosfer Rezervi Olarak Belirlenmesi Üzerine Bir Çalışma. Ankara Üniversitesi Fen Bilimleri Enstitüsü, Doktora Tezi, Ankara. 